\title{
o populismo na construção de uma política externa integrativa: o caso da Venezuela de Hugo Chávez (1999-2013)
}

\author{
Populism in the making of an integrative foreign policy: the case of Venezuela by Hugo Chávez (1999-2013)
}

DOI: $\underline{\text { https://doi.org/10.22456/2178-8839.110774 }}$

Mateus Webber Matos Universidade Federal do Rio Grande do Sul, Porto Alegre, Brasil mateus.webber@hotmail.com

José Antonio Fogolari Universidade Federal de Santa Catarina, Florianópolis, Brasil josefogolari@gmail.com

\begin{abstract}
Resumo
A conceituação de populismo é bastante controversa. Uma das vertentes entende o fenômeno como a adoção de posturas personalistas e centralistas, criando um canal de comunicação direto entre líder e povo. Estes regimes permeiam a história de países latino-americanos, como a Venezuela de Hugo Chávez em 1999. A pergunta central deste trabalho é: de que maneira Chávez se utilizou de seu projeto populista doméstico para dar suporte a uma política externa integrativa na América Latina? O objetivo desse artigo é compreender em que medida práticas como o controle estatal de atividades estratégicas e a criação de arranjos de integração regional - baseadas no populismo personalista de Chávez - moldaram a identidade da política externa venezuelana. Para tanto, foi utilizada a metodologia qualitativa bibliográfica, recorrendo a artigos de periódicos qualificados em português, inglês e espanhol. Do ponto de vista teórico, o Construtivismo e a Análise de Política Externa serão, também, elementos fundamentais para atingir os objetivos propostos em cada capítulo. De forma preliminar, a literatura aponta que o populismo de Chávez - amparado, notadamente, pela renda advinda da exportação de petróleo e do apoio demonstrado pela população venezuelana - possibilitou maior aproximação (ideológica e política) com vizinhos, tais como Bolívia, Equador e Cuba, dando origem a estratégias mais autônomas de desenvolvimento regional em detrimento das premissas neoliberais. Concluiu-se que o governo de Chávez, contudo, não expandiu suas parcerias pela região de maneira uniforme, tampouco logrou erradicar as disparidades econômicas venezuelanas.
\end{abstract}

Palavras-chave: Populismo; Política Externa; Venezuela; Análise de Política Externa;

\begin{abstract}
A concept of populism is quite controversial. One strand understands the phenomenon as the adoption of personalist and centralist positions, creating a direct communication channel between leader and people. These regimes permeate the history of Latin American countries, such as Venezuela by Hugo Chávez in 1999. A central question in this work: how would Chávez use his populist domestic project to support an integrating foreign policy in Latin America? The purpose of this article is to understand the extent to which practices such as state control of strategic activities and the creation of regional integration schemes - based on Chávez's personalist populism - to shape the identity of Venezuelan foreign policy. To this end, the qualitative bibliographic methodology was used, including articles from qualified newspapers in Portuguese, English and Spanish. From the theoretical point of view, Constructivism and Foreign Policy Analysis will also be fundamental elements for the achievement of the objectives proposed in each chapter. Preliminarily, the literature points out that Chávez's populism - sustained, notably, by the rise of oil exports and the support shown by the Venezuelan population - made closer ties possible (ideological and political) with neighbors, such as Bolivia, Ecuador and Cuba, giving rise to more autonomous regional development strategies to the detriment of neoliberal premises It is concluded that the Chávez government, however, neither expand its partnerships in the region in an uniform manner, nor managed to eradicate Venezuelan economic disparities.
\end{abstract}

Keywords: Populism; Foreign Policy; Venezuela; Foreign Policy, Analysis;

Recebido: 19 janeiro 2021

Aceito: 22 março 2021 


\section{Introdução}

A política externa venezuelana, durante a primeira metade do século XX, foi largamente baseada na descoberta de vastas reservas de petróleo na década de 1920. A dependência em relação à renda do petróleo como único produto de exportação fez emergir, em 1958, um marco político caracterizado por uma coalização de elevada heterogeneidade social: o sistema puntofijista.1

Esse pacto estabeleceu normas para o funcionamento da democracia venezuelana e uma aliança entre os partidos políticos Acción Democrática, Comité de Organización Política Electoral Independiente e Unión Republicana Democrática (SARAIVA; RUIZ, 2009). Ao longo dos próximos 30 anos, a Venezuela se consolidou como uma democracia cercada por regimes ditatoriais no sul do continente. Conjuntamente, a década de 1970 presenciou um aumento substancial nos preços internacionais do petróleo, o que possibilitou ao governo investir em melhorias sociais (EDWARDS, 2010).

Em 1988, Carlos Andrés Pérez foi eleito para seu segundo mandato (1989-1993) como presidente da Venezuela. A volta de Pérez ao poder fez a população relembrar e desejar o retorno dos tempos de prosperidade de seu primeiro governo (1974-1979). Essas expectativas, entretanto, foram frustradas já em seu discurso de posse em fevereiro de 1989. Pérez anunciou diversas medidas impopulares, dentre elas um aumento de $100 \%$ no preço da gasolina, elevação da cobrança de serviços essenciais (água, luz, telefone), privatização de empresas estatais que ele próprio havia criado cerca de 10 anos antes e acréscimo de 30\% no valor do transporte público (MONTIEL, 2018).

Em 1999, no entanto, o cenário político foi radicalizado com a eleição de Hugo Chávez à presidência. A partir da implementação de medidas ancoradas, notadamente, na renda advinda da exportação de petróleo - tais como estatização de setores centrais da economia, redução dos incentivos à iniciativa privada e o estímulo à organização popular - Chávez construiu sua política externa voltada à integração latino-americana (LOPES, 2012). A relevância deste trabalho reside na tentativa de interligar o populismo venezuelano de Chávez como mecanismo essencial para a concepção de diretrizes externas que visavam a sustentação de seu governo, bem como a propagação dos ideais de união continental concebidos por Simón Bolívar2 nas três primeiras décadas do século XIX.

O objetivo desse artigo, a partir de uma metodologia de pesquisa qualitativa bibliográfica, é compreender de que maneira práticas como o controle estatal de atividades estratégicas e a criação de arranjos de integração regional induziram a identidade da política externa venezuelana para a América Latina ao longo do período chavista. A pergunta à qual esse artigo procura responder, portanto, é: de que maneira Chávez se utilizou de seu projeto populista doméstico para dar suporte a uma política externa integrativa na América Latina?

Para tanto, o marco teórico no qual o presente artigo se fundamenta busca, na complementariedade entre a Teoria Construtivista e a Análise de Política Externa, um caminho para reflexão sobre as dinâmicas externas e internas de determinado Estado, desde as construções de suas identidades até, por consequência, suas tomadas de decisão. Quanto à primeira - na qual os escritos de Nicholas Onuf e Alexander Wendt servirão como as principais fontes de compreensão das premissas teóricas - justifica-se sua utilização no sentido de observar de que forma ocorreu a construção política venezuelana a partir do discurso e do caráter personalista populista de Chávez.

No tocante à Análise de Política Externa, será possível complementar a investigação teórica através da identificação dos processos internos do Estado, processos estes que moldam e garantem legitimidade às tomadas de decisão de seus líderes. Ambos os caminhos teóricos estabelecidos são de grande valia para a compreensão da formação da

\footnotetext{
${ }^{1}$ Na visão de Kirk Hawkins (2010, p.3) “de 1958 até 1998, a Venezuela teve um regime democrático peculiar conhecido como o sistema Punto Fijo, nomeado em homenagem a um pacto assinado por atores políticos importantes durante a transição democrática de 1958 . Esse pacto comprometia todos os partidos a respeitar o resultado das eleições nacionais subsequentes enquanto implementava um conjunto de políticas redistributivas de desenvolvimento econômico alimentadas pela riqueza nacional em petróleo".

${ }^{2}$ Há um intenso debate no campo acadêmico em relação aos reais princípios e pensamentos de Simon Bolívar. Por vezes, enfatiza-se seu caráter antiamericanista; em outras, seus ideais são condenados em face de sua origem abastada. Fato é que "inspirado na saga dos federalistas estadunidenses, Bolívar vislumbrava condições sociais propícias ao autogoverno venezuelano. [...] Bolívar deixaria mais ou menos clara a sua inclinação por um governo unitário e centralizador, ao rejeitar, para a Venezuela, o modelo federativo. [...] A mescla do republicanismo aristocrático do Oitocentos com o desejo de reprimir as convulsões domésticas marcava o pensamento bolivariano original” (LOPES, 2013, p.263-264).
} 
identidade venezuelana chavista, dos processos decisórios internos e, em especial, de suas consequências nas relações externas costuradas por Chávez.

Esse trabalho está dividido em três capítulos, acrescidos das conclusões: o primeiro capítulo abordará algumas definições de populismo com o intuito de promover um debate acerca do termo. Percebida de distintas formas e com diferentes roupagens ao longo da história, a noção de populismo carrega, no âmbito da Ciência Política, uma série de significados e interpretações. A literatura selecionada percorre um caminho argumentativo no sentido de apresentar um conceito multifacetado, associado profundamente aos contextos sociais, econômicos e produtivos de cada região, que refletem, posteriormente, nas tomadas de decisão e estratégias de política externa.

O capítulo seguinte apresenta as bases constitutivas do populismo na era Chávez, a partir dos preceitos do Construtivismo. Neste sentido, a fundamentação teórica escolhida fornece os elementos centrais para observar e identificar, no caso venezuelano, as condições materiais e subjetivas que constituíram a identidade externa do Estado. A intenção é demonstrar - por meio da manifestação dos discursos, ideias e interesses chavistas - que decisões políticas foram tomadas com o objetivo de amealhar apoio popular para legitimar a manutenção da elite institucional vigente.

Por fim, o terceiro capítulo discute a relação entre o populismo e a construção da política externa de Chávez. Ao apropriar-se dos elementos do campo da Análise de Política Externa como complementação à análise teórica construtivista, o capítulo fornece as ferramentas de identificação e observação dos processos internos de tomada de decisão, e da simbiótica relação entre os âmbitos doméstico e internacional.

\section{Debate teórico sobre o conceito de populismo}

Este capítulo inicial versa sobre o debate em torno do fenômeno do populismo e reúne enfoques diversos de pesquisadores do tema. A reflexão avança na medida que são abordados pontos de vistas de autores em diferentes línguas e contextos sociais, o que, no caso específico do populismo, proporciona um panorama multifacetado de exemplos históricos. Antes, contudo, é necessário que se faça uma breve contextualização histórica sobre a construção teórica e a utilização prática do populismo, em especial, na América Latina.

Observa-se que o termo pode ser utilizado para descrever governos com ideologias diametralmente distintas. Há autores que corroboram o argumento de que isso ocorre pelo fato de o populismo não estar atrelado a um campo ideológico, podendo ser utilizado tanto por regimes neoliberais quanto nacional-desenvolvimentistas. Suas raízes estariam mais relacionadas às fraturas sociais dos países e às crises nos sistemas produtivos internacionais. Desse modo, pode-se entender o populismo, sobretudo na América Latina, a partir da noção de que

A urbanização, a industrialização, as transformações tecnológicas e sociais no mundo agrário, a revolução de expectativas e a explosão demográfica, são alguns dos principais fatores apontados na análise das causas e condições da ação das massas nos acontecimentos políticos nacionais. [...] $\mathrm{O}$ populismo é um movimento de massas que surge no centro das rupturas estruturais que acompanham as crises do sistema capitalista mundial e as correspondentes crises das oligarquias latino-americanas. As novas relações de classe começam a se expressar de forma muito mais aberta quando as rupturas políticas e econômicas (internas e externas) enfraquecem decisivamente o poder oligárquico (GERMANI; TELLA; IANNI, 1973, p.83-85). ${ }^{3}$

Apesar destas similaridades, é preciso atentar para a geografia e os níveis de desenvolvimento de cada região. Ao ser analisado a partir da realidade latino-americana, o populismo adquiriu conotação pejorativa, associado a um movimento desorganizado e bárbaro, caracterizado pela improvisação e pela irresponsabilidade (GERMANI; TELLA; IANNI, 1973). Mesmo dentro de um recorte geográfico específico como a América Latina há alguns países que possuem

\footnotetext{
${ }^{3}$ Nas citações traduzidas em que a referência não apresenta o tradutor, a responsabilidade pela tradução é dos autores deste trabalho.
} 
idiossincrasias. No Brasil, por exemplo, os governos de Getúlio Vargas - nas décadas de 1930, 1940 e 1950 - foram alicerces importantes para a criação de uma identidade nacional, tão complicada dada a extensão territorial do país.

Uma abordagem anglo-saxã do tema refere-se ao populismo como um conceito político notadamente moldado por processos socioeconômicos, cujo referencial teórico reside na Teoria da Dependência e em tendências econômicoestruturalistas. Desse modo, expressões como “desenvolvimento" e "subdesenvolvimento" tornam-se chave para o entendimento das variantes do termo e suas raízes, principalmente nos regimes que se estendem da década de 1930 a 1960 , conhecidos como "populismo clássico” (WEYLAND, 2001). Sendo assim, pode-se inferir que, para a manutenção política do sistema é fundamental que se invista em programas sociais expansionistas e de distribuição de renda.

Por outro lado, há pesquisadores que enxergam no populismo uma construção política alicerçada em discursos e em um conjunto de valores, cujo objetivo é criar uma dicotomia entre o "bem” e o "mal”. O primeiro é representado pela figura do líder e de seu amplo apoio popular, e o segundo é, via de regra, uma representação de uma elite dominante e opressora com a qual deve-se romper todo e qualquer jugo ou relação de submissão (HAWKINS, 2010). A aceitação, por parte da população, desse discurso perpassa uma série de fatores, tais como o carisma da liderança, a escolha de elementos linguísticos simples e investimentos que deem conta de atender às demandas sociais.

Muito embora essa prática de polarização política represente um suspiro de dignidade à população ela pode ser prejudicial ao funcionamento das instituições do governo. De acordo com Kirk A. Hawkins (2010, p.7) “(...) movimentos populistas tipicamente se provam incapazes de resolver esses problemas básicos. Isso ocorre porque eles desprezam as formalidades institucionais e burocracias imparciais que o Estado de Direito exige”. Os problemas citados pelo autor dizem respeito à corrupção dentro dos órgãos governamentais e à incapacidade nacional de manter um desenvolvimento econômico minimamente constante e igualitário.

Outro ponto negativo diz respeito às barreiras impostas por esses governos às empresas transnacionais que desejam explorar algum recurso dentro do território. Há uma certa proeminência dada à indústria nacional, principalmente em setores que são estratégicos, tais como o energético e a construção civil. Nesse ínterim, fortalecem -se os grupos sindicais e a burguesia nacional. Assim, Paul Cammack (2000, p.151) descreve as principais características do populismo como sendo "a proeminência do líder, a relativa fraqueza dos partidos e da legislatura, e o uso de instituições corporativistas para organizar os negócios e para mobilizar e controlar o trabalho”. Por seu turno, pensadores latino americanos, em alguns casos, sequer mencionam o termo dentro do contexto do subcontinente. Quando o fazem, percebese uma tentativa de análise mais social e pautada nos avanços do que propriamente no subdesenvolvimento dos países. A ênfase, nesses casos, é dada ao contraste entre os governos populistas e seus antecessores, cujas críticas mais substanciais residem na violação da soberania do país em detrimento da implementação de políticas neoliberais (VILAS, 2004).

No decorrer da década de 1980, com a ascensão das políticas neoliberais, há uma busca por desvincular o populismo de um engessamento histórico, ressaltando sua atemporalidade e suas características regionais. A recepção dessa reformulação do conceito, todavia, não resultou na mudança de percepção por parte de pesquisadores de países centrais. De acordo com Antônio Mitre (2008, p.11)

O fenômeno populista passou, então, a ser entendido como uma doença crônica que aflige sobretudo regimes de esquerda, levando-os a adotar políticas fiscais na contramão do que aconselharia a boa teoria econômica. Nessa linha exegética, os governos acometidos pelo vírus populista, [...] apostam em medidas macroeconômicas que estimulam o aumento do gasto público e dos salários, em detrimento de programas tendentes a elevar gradualmente a produtividade.

O fim da década de 1990, especificamente na Venezuela, foi palco da emergência de um dos líderes latinoamericanos mais emblemáticos do século: Hugo Chávez. Seu governo é considerado um dos expoentes populistas mais relevantes da região, uma vez que foram implementadas diretrizes de sufocamento dos partidos políticos tradicionais, crescente personificação da figura presidencial e maior proximidade entre Chávez e lideranças populares (VILAS, 2004). 
Amparado na receita vinda da exportação do petróleo, Chávez deu início a uma série de reformas políticas e econômicas com o intuito de fortalecer a presença do Estado e buscar a integração com países vizinhos. O cenário, entretanto, não era favorável a Chávez, haja vista que, no período de sua eleição, "economicamente, houve uma redução de $1 \%$ no PIB petroleiro, os investimentos privados caíram, o desemprego alcançou 12\%, os salários diminuíram 4\%” (SAAVEDRA, 2009, p.229).

\section{O populismo na era Chávez sob o prisma da Teoria Construtivista}

No presente capítulo pretende-se fazer uma breve revisão dos escritos sobre o Construtivismo e relacioná-los ao caso específico da formação da política externa da Venezuela de Hugo Chávez. Partiremos da premissa de que o populismo - como fenômeno social - é construído a partir de discursos e das estreitas relações entre a figura de Chávez e a população venezuelana. Sendo assim, para-Nicholas Onuf (2013, p.4) - um dos fundadores do pensamento construtivista - “dizer é fazer: falar é, sem dúvida, a maneira mais importante que fazemos para tornar o mundo como ele é”.

Ao criar canais de comunicação mais diretos, Chávez e a sociedade venezuelana fizeram parte de um processo de construção de um relacionamento de confiança e respeito mútuos. Para isso, o discurso como instrumento de legitimação do status quo e adesão social são imprescindíveis. Essas manifestações demonstram sua relevância uma vez que "a recuperação do discurso bolivariano [...] tem uma eficácia política importante, na medida em que oferece a um discurso abstrato um sentido concreto. Chávez tem feito do discurso bolivariano um instrumento concreto de ação política” (VILLA, 2005, p.160).

O Construtivismo, no entanto, não deve ser considerado uma teoria de política internacional. Busca, antes de tudo, analisar a construção social dos atores envolvidos em uma relação (WENDT, 1999). No caso venezuelano, Chávez forjou uma estrutura assentada, em grande medida, no apoio às reivindicações das massas e, reciprocamente, recebeu suporte político para se legitimar no poder. A fragmentação da base de oposição ao seu governo e o enfraquecimento dos partidos políticos permitiram a Chávez consolidar suas reformas mais prementes.

O populismo chavista contou com grande coesão social, contudo, foi responsável pelo surgimento de um vácuo institucional, que passou a ser ocupado por organizações e grupos com questionável capacidade técnica (VILLA, 2005). Essa aparência de legalidade na condução da política doméstica esconde graves problemas, tais como a supressão de direitos constitucionais e a deformação do modelo democrático. Segundo Almeida (2014, p.90), analistas políticos tendem a acreditar que alguns regimes democráticos latino-americanos carregam forte semelhança com as ditaduras que assolaram o continente na segunda metade do século XX e que "a contrapartida é que se caiu, em vários casos, em simulacros de democracia, regimes eletivos que derivam para o populismo plebiscitário, ou mesmo em contrafações do cesarismo e do bonapartismo, por meio dos quais se degrada e se deforma a noção mesma de democracia”.

Pode-se explicar esse cenário venezuelano segundo uma perspectiva construtivista de que todo regime ou sistema social possui três elementos-chave: condições materiais, interesses e ideias (WENDT, 1999). Todos foram mutuamente constituídos e deram sustentação à presidência de Chávez. O primeiro elemento é facilmente identificável: o petróleo. A Petróleos de Venezuela S.A. (PDVSA), empresa estatal responsável pela exploração da commodity que representa $80 \%$ das exportações venezuelanas e 25\% de todo o PIB do país, cumpre um papel essencial na compreensão do contexto econômico e social domésticos (CARRA, 2008). Em relação ao segundo elemento (interesses) Chávez procurou proteger e fomentar o desenvolvimento de classes sociais esquecidas pelos regimes anteriores. Para isso, seu carisma e os recursos advindos da venda de petróleo foram fatores cruciais.

Por fim, o terceiro elemento é caracterizado pelos ideais bolivarianos de Chávez. Para Herz (1994, p.80) é importante notar que "no caso do estudo de processos decisórios, embora o peso das variáveis subjetivas seja considerado, o ponto nevrálgico são as tomadas de decisões”. A partir desse entendimento, o ato de comungar uma ideologia (variável subjetiva) deve ser acompanhado de decisões assertivas no campo da política externa. Sendo assim, as estratégias de 
aproximação regional - Bolívia, Cuba e Equador - são valiosas para a compreensão de uma política externa integrativa apoiada nos dois primeiros elementos supracitados (condições materiais e interesses).

Essa tentativa de harmonização política respeitou as realidades sociais e econômicas de cada país, sem, contudo, deixar de partilhar ideias e valores comuns ao bolivarianismo. Tais governos são parte de um processo de ruptura que, de acordo com Reinaldo Gonçalves (2009, p.202),

(...) é particularmente relevante quando se considera que os novos modelos têm clara orientação socialista ainda que haja inúmeras indefinições e distinções. Vale destacar que este fato assume uma dimensão histórica extraordinária não somente na América Latina, mas também no contexto da história mundial contemporânea. Neste contexto de transformações globais do início do século XXI, os processos de ruptura via projetos de orientação socialista - principalmente na Venezuela - representam marcos históricos para a América Latina e o conjunto dos países em desenvolvimento.

Por outro lado, o Construtivismo pode ser aplicado também em contextos sociais cujo processo de desenvolvimento não foi de todo exitoso. Ao fazer uma comparação dos índices de desenvolvimento entre a Venezuela e o México entre 1998 e 2005, Castañeda (2006) afirma que Chávez pouco fez para auxiliar a classe social mais pobre, priorizando relações internacionais com estados periféricos e que pouco tinham a contribuir para a economia venezuelana. Argentina, Bolívia, Cuba, Equador, Irã e Peru são alguns exemplos de parcerias firmadas por Chávez tendo em vista a polarização da política do continente americano em dois grupos: um pró-Venezuela e outro pró-Estados Unidos da América (CASTAÑEDA, 2006).

No entanto, conforme citado nos parágrafos anteriores, essa abordagem depreciativa do populismo de Chávez não impede a realização de análises sobre a realidade da Venezuela, amparadas no Construtivismo. Isso ocorre porque esta corrente de pensamento está mais aberta às particularidades locais do que as teorias dominantes, como o Realismo e o Liberalismo. Segundo Erik Jorgensen (2001, p.12) “(...) mesmo que o construtivismo seja mais aberto [...] a aspectos de mudança ou transformação na política mundial, não significa que a mudança em questão necessariamente será progressiva, ou seja, constituirá uma mudança pra melhor”.

Entretanto, toda mudança política dentro das fronteiras de um estado é complexa e repleta de peculiaridades. Apesar de alguns autores associarem o Construtivismo a um processo relativamente simples, este - ao ser sustentado pela interação da sociedade e da estrutura - varia de acordo com a imprevisibilidade humana (WENDT, 1999). Portanto, o caso venezuelano torna-se mais emblemático ainda, dado que os 40 anos em que vigoraram o sistema democrático puntofijista foram encerrados por um modelo populista com diretrizes de política externa diametralmente opostas às praticadas até 1999.

A Constituição do mesmo ano solapou as estruturas dos governos que antecederam Chávez, buscando reformas na democracia venezuelana que garantissem melhores condições aos estratos sociais menos favorecidos e, com isso, conquistassem o apelo popular (LOPES, 2012). O êxito chavista se deu dentro de um panorama de sufocamento das lideranças contrárias ao seu projeto e ao discurso crítico em relação ao esgotamento do sistema de Punto Fijo, que não mais contava com a adesão da sociedade. De acordo com Rafael Villa (2005, p.159) "para a emergência de Chávez, contribuíram consideravelmente tanto os erros de alguns de seus adversários, como o profundo sentimento de rejeição aos partidos tradicionais que manifestavam os venezuelanos”. Desse modo, nota-se que o arcabouço reformista de Chávez não foi implantado sem apoio social.

O Construtivismo, por fim, nos auxiliou no entendimento dos métodos de Chávez para o estreitamento dos laços entre líder e povo, baseados no aumento da distribuição de renda e de seu carisma. Além disso, foi possível observar, através de uma lente construtivista, como ocorreu o forjamento das bases de apoio popular necessárias para a projeção de um plano regional integrativo. Chávez, portanto, logrou arquitetar um governo de cunho personalista para implementar políticas bolivarianas em âmbito latino-americano. 


\section{A influência do populismo de Chávez na construção de uma política externa integrativa para a América Latina}

Do ponto de vista da literatura científica do campo da Análise de Política Externa, o conceito de populismo e sua vinculação com o processo de tomada de decisão de governantes ainda carece de aprofundamentos e tem recebido maior atenção acadêmica em pesquisas na área apenas recentemente. Na visão de Wehner e Thies (2020, p.2) "Na verdade, a literatura considera a dimensão internacional do populismo como um fenômeno social monolítico, concebido como antiplural, antidemocrático e anticosmopolita”. Por outro lado, a compreensão do conceito de modo amplificado, considerando suas possíveis e variadas aparências, fornece ao pesquisador ferramentas para melhor identificação de como se manifesta a relação entre populismo e política externa.

De modo geral, o conceito de populismo não se refere de maneira imediata a uma conduta específica e uniforme de política externa, algo estanque e visivelmente delineado. Traduz, entretanto, uma série de movimentos, "inclui narrativas de elite versus povo e a vontade geral, a fim de fazer uma política externa mais ou menos populista” (WEHNER; THIES, 2020, p.3). Não há, portanto, uma definição do termo que não careça de contextualização para a compreensão na política externa. O que podemos identificar, contudo, na visão de Werbeeck e Zaslove (2017, p.16) “é uma variedade de posturas entre os tipos de populismo, variando de políticas isolacionistas até posturas mais amplas em relação ao cosmopolitismo ou até um tipo de cosmopolitismo social. [...] Essas posturas dependem, em parte, da relação entre populismo e a ideologia anexa”.

Há, portanto, apesar das distintas formas de manifestação do populismo, elementos em comum que podem ser compreendidos nos processos de tomada de decisão em política externa. Como abordado anteriormente, o processo de rivalização e criação de antagonismos e inimigos é a tônica na manutenção da narrativa populista e manifesta a luta pelo poder na dicotomia entre os extremos, frequentemente identificados como: povo e elite. Esse processo de embate, que acirra os ânimos internos abre espaço para "inseguranças que narrativas de política externa provocam nas elites nacional e cosmopolita, assim como em outros estados e suas respectivas lideranças que são, do ponto de vista do líder, construídas como inimigas, rivais e amigáveis” (WEHNER; THIES, 2020, p.15).

Hugo Chávez, neste sentido, soube se utilizar desses mecanismos de antagonismo de forma frequente em seus discursos públicos. Colocando-se ao lado do povo, o líder venezuelano inflamou por vezes seus partidários contra seus inimigos: a elite e o imperialismo liberal norte-americano. Com base em princípios de autonomia e de ruptura da dependência colonialista, "Chávez apresentou narrativas de papeis rivais antagônicos, isto é, o povo versus a elite, que eram não somente domésticas por natureza, mas impactaram no relacionamento com os Estados Unidos” (WEHNER; THIES, 2020, p.12).

Ao associar sua liderança populista aos princípios revolucionários de Simón Bolívar, Chávez buscou forjar em sua política externa personalista uma identidade de oposição aos valores liberais das elites, manifestadas sobretudo por meio do neocolonialismo norte-americano. Na prática, foi capaz de ganhar adeptos e aliados tanto no âmbito interno, que garantiram sua sustentação no poder, quanto externo, em suas relações com estados vizinhos. Nesse sentido, "identidades sociais e políticas podem ser definidas primeiramente em termos de nacionalidade, mas na América Latina diferenças ideológicas ou projetos políticos alternativos também podem servir para definir as identidades coletivas de atores políticos” (TRINKUNAS, 2009, p.5).

Além disso, outros objetivos políticos e sociais também conduziam a uma maior aproximação da Venezuela de seus vizinhos, como por exemplo "modificar os equilíbrios geopolíticos regionais e mundiais. Ainda, a dimensão social da integração - que inclui a luta contra a pobreza e a exclusão, assim como a consulta e participação da sociedade civil” (ROMERO; CARDOZO, 2002, p.161). Isso indica uma possível mudança de comportamento desses novos processos de integração latino-americana em direção à políticas de redução de desigualdades e outras pautas que começavam a ganhar notoriedade. 
Do ponto de vista econômico, por depender quase que exclusivamente da exploração e exportação de somente um produto, a Venezuela tem, historicamente, sofrido constantes períodos de volatilidade. Na esteira da crise norteamericana do subprime, do desequilíbrio fiscal e de anos de gastos sociais expressivos, a Venezuela registrou uma alta da inflação (entre maio e dezembro de 2010) de 16\% para as camadas mais pobres e de 38,2\% para os considerados miseráveis, a despeito do crescimento médio do PIB de 9\% entre 2004 e 2007 (ARENAS, 2010).

Nessa linha, uma das medidas de Chávez, em 2001, foi a elaboração da Lei Orgânica dos Hidrocarbonetos, cujo propósito primordial era a reversão dos lucros gerados pela venda de petróleo em prol do desenvolvimento social do país (BRUCE, 2008). Sob qualquer ponto de vista, a PDVSA é instrumento indispensável para a compreensão desse cenário, uma vez que "também tem contribuído decisivamente na elevação dos gastos sociais, além de constituir-se na principal fonte de receitas do Estado" (LOPES, 2012, p.288).

Ademais, a estatal também exerce forte poder político dentro de outras searas governamentais, a saber a da política externa. Em 2005 a PDVSA expandiu seus negócios e abriu escritório na China, o que mostrava a disposição de Chávez em promover uma inflexão ao capital chinês (SHIFTER, 2006). Essas duas facetas da gigante petroleira representam um interessante instrumento daquilo que Robert Putnam chamou de “Jogos de Dois Níveis”. Na visão de Putnam (2010, p.151)

No nível nacional, os grupos domésticos perseguem seu interesse pressionando o governo a adotar políticas favoráveis a seus interesses e os políticos buscam o poder constituindo coalizões entre esses grupos. No nível internacional, os governos nacionais buscam maximizar suas próprias habilidades de satisfazer as pressões domésticas, enquanto minimizam as consequências adversas das evoluções externas. No nível internacional, os governos nacionais buscam maximizar suas próprias habilidades de satisfazer as pressões domésticas, enquanto minimizam as consequências adversas das evoluções externas.

Em outras palavras, as políticas doméstica e internacional têm a capacidade de se influenciarem mutuamente. Como consequência, os fatores vinculados ao âmbito doméstico frequentemente auxiliam a explicar a forma pela qual se manifestam os interesses dos atores e instituições, bem como as ideologias por eles identificadas nos processos de tomada de decisão. Assim, conforme Wehner e Thies (2020, p.4), "para entender os papeis que governos populistas concebem e desempenham internacionalmente, devemos atentar para as políticas domésticas, uma vez que o populismo inicia ali e ganha significado internacionalmente através de sua interação com densas ou outras ideologias tênues”.

Todavia, o debate não deve ser interrompido neste ponto, e sim levado a responder questões mais complexas: “quando influencia” e "como influencia”, por exemplo (PUTNAM, 2010). Por isso, o caso da PDVSA é aqui abordado. Ao mesmo tempo que participou ativamente do regime populista de Chávez - ora como financiadora de planos de infraestrutura, ora agente modelador da sociedade - a companhia também tinha interesses que iam além das fronteiras venezuelanas e que perpassavam pela construção da diplomacia estatal. Segundo Saavedra (2009) a utilização da política externa pelo Estado seria a alternativa que apresentaria os menores custos e, em contrapartida, maiores benefícios, sejam eles materiais, econômicos, humanos, diplomáticos, psicológicos ou sociais.

No decorrer do segundo mandato do governo Chávez (2007-2013), após intenso processo de consolidação na presidência, foi lançado o Plano Nacional de Desenvolvimento Econômico e Social da Nação, fruto de uma ampla reforma institucional. A meta principal desta reforma era o florescer de uma "Nova Ética Socialista” 4, em cuja plataforma residiam propostas como a diminuição da exclusão social, a construção de uma sociedade baseada no humanismo de Simón Bolívar e o fortalecimento de uma democracia que primasse pela força coletiva (MAYA; LANDER, 2009).

\footnotetext{
${ }^{4}$ De acordo com o documento oficial venezuelano intitulado Líneas Generales del Plan de Desarrollo Económico y Social de la Nación 2007-2013 (LGPDESN, 2007), a Nova Ética Socialista pode ser entendida na medida que "a plena realização do Socialismo do Século XXI que estamos inventando, e que só será possível em um intervalo histórico, passa necessariamente pela refundação ética e moral da nação venezuelana. Tal refundação supõe um projeto ético e moral que tenha suas raízes na fusão dos valores e princípios das mais avançadas correntes humanistas do Socialismo e da herança histórica do pensamento de Simón Bolívar”.
} 
Outro ponto de vista, no entanto, ressalta que esse contexto reformista foi arriscado para a sociedade venezuelana, em um primeiro plano, e às relações internacionais do país em uma perspectiva mais ampla. A nacionalização de recursos primários, a adoção de uma postura mais agressiva frente aos Estados Unidos e aos organismos internacionais - a saber, o Fundo Monetário Internacional (FMI) e o Banco Interamericano de Desenvolvimento (BID) -, o discurso crítico em relação ao corolário neoliberal e o desapreço às demandas sociais internas são tidos como aspectos da nova postura populista que colaboraram para certa instabilidade política do regime de Chávez (LOPES, 2013).

Foi nesse ínterim que ocorreu a criação da Alternativa Bolivariana para as Américas (ALBA) ${ }^{5}$ em 2004. A ALBA nasceu dos esforços da política externa integrativa de Chávez para o subcontinente latino-americano, guiada por valores anti-imperialistas, autonomistas e de coordenação política regional (ROMERO e CARDOZO, 2002). Isso mostra que a Venezuela é um agente ativo dentro das relações internacionais, refutando uma postura isolacionista e sendo partícipe de organizações regionais de cooperação (LOPES, 2013). Dessa forma, a construção ideológica da ALBA foi um projeto amparado, sobretudo, na aprovação interna que Chávez detinha. Isso colaborou para a consolidação de sua imagem de liderança regional carismática.

No tocante à importância do petróleo e do apoio popular de Chávez nessa empreitada "não há dúvida de que constituem uma peça inestimável da estratégia venezuelana, que se traduziu em um fortalecimento da liderança e da influência de Chávez, não somente em âmbito regional, mas também no cenário internacional” (URRUTIA, 2006, p.169). Outros mecanismos utilizados pela política externa venezuelana na década de 2000 foram a tentativa de aproximação com a União Europeia e uma maior participação na OPEP.6 Enquanto a primeira era vista como uma oportunidade de estreitamento das relações com países desenvolvidos a segunda dizia respeito a uma política de valorização do preço internacional do petróleo (VIZENTINI, 2001).

Com o propósito de legitimar seu regime internacionalmente, Chávez se utilizou em grande medida da diplomacia presidencial, com base em seu centralismo político, visitando diversos parceiros econômicos tais como Iraque, Rússia e China. O regime populista de Hugo Chávez representou uma alternativa aos países periféricos que buscavam um desenvolvimento mais autônomo com seus vizinhos fronteiriços.

O populismo chavista de caráter revolucionário teve maior capacidade de reverberação, em especial, na América Latina, onde as convergências ideológicas e materiais se sustentam de forma semelhante, com base na superação da condição de dependência para a construção de uma agenda autônoma. O que singularizava a política externa de Chávez eram menos suas estratégias e mais seus propósitos, sendo o principal deles salvaguardar a revolução bolivariana então em curso (TRINKUNAS, 2009).

\section{Considerações finais}

Esse trabalho se propôs a debater a influência do populismo de Hugo Chávez na delimitação de uma política externa venezuelana mais integrativa na primeira década do século XXI. A partir de uma análise sociopolítica - em detrimento de uma puramente econômica - percebemos que as medidas internas adotadas por Chávez fazem parte de um projeto cujos princípios e valores ultrapassaram as fronteiras do país. Dessa forma, foi possível se favorecer de uma sintonia ideológica regional que permitiu a esses países criar uma alternativa ao desenvolvimento neoliberal predominante durante os anos 1990. Líderes como Fidel Castro, Michelle Bachelet, Evo Morales, Rafael Correa, Cristina

\footnotetext{
${ }^{5}$ De acordo com Thomas Muhr (2010, p.615) “em geral, a ALBA é retratada simplesmente como um bloco de Estados de (atualmente) nove membros (Antígua e Barbuda, Cuba, Bolívia, Dominica, Equador, Honduras, Nicarágua, São Vicente e Granadinas e Venezuela). [...] A ALBA opera em dimensões múltiplas interdependentes e complementares, que classifico como político-ideológica, cultural, de energia, social, econômico-industrial, ambiental, militar, financeira, educacional e de conhecimento".

${ }^{6}$ Desde o surgimento da OPEP, em 1960, a Venezuela cumpriu papel importante dentro da organização. Indo ao encontro do exposto por Vizentini acima "a fundação da OPEP ocorreu dentro da estrutura do processo de emancipação de um significativo número dos países do terceiro mundo, período que foi caracterizado pelo débil preço das matérias-primas, que era particularmente evidente no caso do petróleo. [...] No caso específico da OPEP, sua fundação foi fruto de uma tensa correlação de forças entre as companhias de petróleo multinacionais e os países produtores” (CARO, 2001, p.15).
} 
Kirchner e Luiz Inácio Lula da Silva - apesar de possuírem posições políticas por vezes distintas - partilhavam de um sentimento de união hemisférica e questionamento à ordem internacional vigente.

O Construtivismo possibilitou maior entendimento de como se dão as relações entre a sociedade e seu líder na estruturação de uma política externa. Para isso, foi realizado um estudo da participação da estatal petroleira PDVSA na construção de uma elite hegemônica que passou a controlar as riquezas do país, impactando diretamente na distribuição de renda à população. Essa elite, além de poder econômico, detinha considerável influência política sobre o governo de Hugo Chávez, inclusive no planejamento das relações internacionais da Venezuela. Por ser uma das maiores companhias das Américas, à PDVSA era fundamental expandir os mercados nos quais atuava.

A teoria Construtivista e a APE auxiliaram, respectivamente, no entendimento dos âmbitos internos e externos da Venezuela. Fazendo uso de suas ferramentas, o Construtivismo permitiu a análise das estratégias de Chávez para consolidar sua presidência e aproximar-se dos venezuelanos. Nessa lógica, as condições materiais, os interesses e as ideias foram os três fatores que ajudaram a compreender o modus operandi chavista. A APE, por sua vez, foi de grande valia para a parte final da pesquisa. Auxiliou na busca por indícios que fundamentassem a tentativa de Chávez em seguir os ideais de Bolívar e aprofundar a integração de países latino-americanos.

A complementariedade entre Construtivismo e APE ofereceu ferramentas para reconhecer as identidades de alguns atores (políticos, sociais e econômicos) venezuelanos e como eles interferiram no processo de tomada de decisão do governo Chávez, tanto doméstica quanto internacionalmente. O discurso e as características personalista e carismática do líder venezuelano também contribuíram para o entendimento das nuances de seu populismo. Todos esses elementos se fundem com a finalidade de preservar os ideais bolivarianos, em especial, na Venezuela, mas também em grande parte da América Latina.

A contribuição dessa pesquisa se encontra na interligação entre o populismo implementado internamente por Chávez e a condução de uma política externa integrativa para o seu entorno hemisférico. Para além de uma simples iniciativa de integração regional, o projeto de Chávez previa a contestação do status-quo econômico e político internacional. Com o apoio de seus vizinhos, foi possível, em alguma medida, questionar a ordem mundial e forjar um modelo de desenvolvimento mais autônomo e preocupado com as realidades locais. Entende-se que o populismo cumpriu papel importante para a consolidação de Chávez no poder, bem como legitimou as escolhas políticas para a integração regional.

\section{Referências}

ALMEIDA, Paulo Roberto de. A grande fragmentação na América Latina: Globalizados, Reticentes e Bolivarianos. Carta Internacional, v.9, n.1, p. 79-93, 2014.

ARENAS, Nelly. La Venezuela de Hugo Chávez: rentismo, populismo y democracia. Nueva Sociedad, n.229, p. 76-93, 2010.

BRUCE, Iain. The Real Venezuela: Making Socialism in the 21th Century. $1^{\mathrm{a}}$ ed. Londres: Pluto Press, 2008.

CAMMACK, Paul. The resurgence of populism in Latin America. Bulletin of Latin American Research, n.119, p. 149-161, 2000.

CARO, Ariela Ruiz. El papel de la OPEP en el comportamiento del mercado petrolero internacional. Santiago do Chile: Nações Unidas, 2001.

CARRA, Marcos. Petróleo e integração energética da América do Sul. In: CEPIK, Marco. América do Sul: Economia e Política da Integração Regional (Org.). Porto Alegre: Editora UFRGS, 2008, p. 119-145.

CASTAÑEDA, Jorge. Latin America's Left Turn. Foreign Affairs, v.85, n.3, p. 28-43, 2006.

CERVO, Amado Luiz. A Venezuela e seus vizinhos. In: GUIMARÃES, Samuel Pinheiro; CARDIM, Carlos Henrique. Venezuela: Visões Brasileiras (Org.). Brasília: IPRI, 2001, p. 157-178.

EDWARDS, Sebastian. Left Behind: Latin America and the false promise of populism. Chicago: Chicago University Press, 2010.

GERMANI, Gino; TELLA, Torcuato di; IANNI, Octavio. Populismo y contradicciones de clase em Latinoamérica. $1^{\mathrm{a}}$ ed. Cidade do México: Serie Popular Era, 1973. 
GONÇALVES, Reinaldo. Venezuela: rupturas e macrocenários. Revista Oikos, v.8, n.2, p. 201-222, 2009.

HAWKINS, Kirk. Venezuela's Chavismo and Populism in Comparative Perspective. $1^{\text {a }}$ ed. Nova Iorque: Cambridge University Press, 2010.

HERZ, Mônica. Análise cognitiva e política externa. Contexto Internacional, v.16, n.1, p. 75-89, 1994.

JORGENSEN, Knud Erik. Four Levels and a Discipline. In: JORGENSEN, Knud Erik; FIERKE, Karin. Constructing International Relations: The next Generation. Nova Iorque: Routledge, 2001, p. 01-19.

LOPES, Ademil Lucio. A Política Econômica e as Estratégias de Desenvolvimento do Governo Chávez. Brazilian Journal of International Relations, v.1, n.2, p. 280-308, 2012.

LOPES, Dawisson Belém. A Economia Política da Década Bolivariana: instituições, sociedade e desempenho dos governos em Bolívia, Equador e Venezuela (1999-2008). Revista Estudos Políticos, n.6, p. 261-277, 2013.

MAYA, Margarita López; LANDER, Luis. El Socialismo rentista de Venezuela ante la caída de los precios petroleros internacionales. Cuadernos Del Cendes, n.71, p. 67-87, 2009.

MITRE, Antônio. As peregrinações de um conceito: populismo na América Latina. Cadernos de História, v.10, n.13, p. 9-23, 2008.

MONTIEL, Inés Quintero El siglo XX: conquista, construcción y defensa de la democracia. In: ITURRIETA, Elias Pino (coord.). Historia mínima de Venezuela. $1^{\text {a }}$ ed. Cidade do México: Turner, 2018, p. 141-231.

MUHR, Thomas. Venezuela e ALBA: regionalismo contra-hegemônico e ensino superior para todos. Educação e Pesquisa, v.36, n.2, p. 611-627, 2010

ONUF, Nicholas Greenwood. Making Sense, Making Worlds: Constructivism in social theory and international relations. $1^{\mathrm{a}}$ ed. Nova Iorque: Routledge, 2013.

PUTNAM, Robert. Diplomacia e Política Doméstica: a lógica dos jogos de dois níveis. Revista de Sociologia e Política, v.18, n.36, p. 147174,2010 .

República Bolivariana de Venezuela. Líneas Generales del Plan de Desarrollo Económico y Social de la Nación $2007-2013.2007$. Disponível em: <http://www.mppp.gob.ve/wp-content/uploads/2013/09/Plan-de-la-Naci\%C3\%B3n-2001-2007.pdf >. Acesso em: 27 abr. 2018

ROMERO, María Teresa; CARDOZO, Elsa. Aproximación a la propuesta internacional de Hugo Chávez: las concepciones de democracia e integración. Revista Venezolana de Análisis de Coyuntura, v.8, n.1, p. 153-173, 2002.

SARAIVA, Miriam Gomes; RUIZ, José Briceño. Argentina, Brasil e Venezuela: as diferentes percepções sobre a construção do Mercosul. Revista Brasileira de Política Internacional, v.52, n.1, p. 149-166, 2009.

SAAVEDRA, Karesly. Aciertos y desaciertos de la política exterior venezolana, 1998-2008. Revista Politeia, v.32, n.42, p. 227-250, 2009.

SHIFTER, Michael. In Search of Hugo Chávez. Foreign Affairs, v.85, n.3, p. 45-59, 2006.

TRINKUNAS, Harold. The logic of Venezuela foreign policy during the Chavez Period. In: CLEM, Ralph; MAINGOT, Anthony. Venezuela 's petro-diplomacy: Hugo Chavez`s foreign policy. Miami: University Press of Florida, 2011. p. 16-30

URRUTIA, Edmundo González. Las dos etapas de la política exterior de Chávez. Nueva Sociedad, n.205, p.159-171, 2006.

VILAS, Carlos. ¿Populismos reciclados o neoliberalismo a secas? El mito del neopopulismo” latinoamericano. Revista de Sociologia e Política, n.22, p. 135-151, 2004.

VILLA, Rafael Duarte. Venezuela: mudanças políticas na era Chávez. Estudos Avançados, v.19, n.55, p. 153-172, 2005.

VIZENTINI, Paulo Fagundes. A Política Externa da Venezuela frente a Globalização (1989-2001). In: GUIMARÃES, Samuel Pinheiro; CARDIM, Carlos Henrique. Venezuela: Visões Brasileiras (Org.). Brasília: IPRI, 2001, p. 57-83.

WENDT, Alexander. Social Theory of International Politics. $1^{\text {a }}$ ed. Nova Iorque: Cambridge University Press, 1999.

WEHRNER, Leslie; THIES, Camaron. The nexus of populism and foreign policy: The case of Latin America. International Relations, jul. 2020. Disponível em: <https://journals.sagepub.com/doi/full/10.1177/0047117820944430>. Acesso em: 16 jan. 2021.

WERBEECK, Bertjan; ZASLOVE, Andrej. Populism and Foreign Policy. Oxford University Press, 2017. Disponível em: <https://people.unica.it/fulvioventurino/files/2020/04/Verbeek-Zaslove_2017_Populism-and-foreign-policy.pdf>. Acesso em: 16 jan. 2021.

WEYLAND, Kurt. Clarifying a Contested Concept: Populism in the Study of Latin American Politics. Comparative Politics, v.34, n.1, p. $1-22,2001$. 
Funções de colaboração exercidas

Mateus Webber Matos:

José Antonio Fogolari:
Conceituação; Metodologia; Validação; Curadoria de dados; Administração do projeto; Visualização; Análise formal; Recursos; Obtenção de financiamento; Software; Investigação; Supervisão; Escrita (primeira redação); Escrita (revisão e edição);

Conceituação; Metodologia; Validação; Análise formal; Escrita (revisão e edição);

Informações fornecidas pelos autores de acordo com a Taxonomia de Funç̃oes de Colaborador (CRediT) 